\title{
Polisemia
}

\section{LA ACCIÓN PÚBLICA DEPORTIVA: UN PROYECTO DE INTEGRACIÓN E INSERCIÓN SOCIAL EN FRANCIA}

\author{
Por Fernando Segura M. Trejo ${ }^{7}$
}

\section{Resumen}

E artículo gira en torno al "Campeonato Inter-asociativo de lucha contra la exclusión social", programa llevado a cabo en la periferia de Paris con la intención de fomentar, mediante la promoción del futbol, los vínculos sociales de personas en situación de exclusión y estigmatización social. Se analiza la historia de dicho campeonato, su organización, la composición de los equipos y las actividades desarrolladas con relación al fútbol. Aunque el autor concluye que el deporte no constituye una solución infalible al problema de la inserción social, destaca lo significativo del programa al garantizar un espacio de convivencia, interacción, disciplina y motivación.

\section{Palabras Claves}

Integración, Inserción social, exclusión social, fútbol, respeto, convivencia

\section{SPORTS PUBLIC ACTION: AN INTEGRATION AND SOCIAL INCLUSION PROJECT IN FRANCE}

\section{Abstract}

The article revolve around the "Campeonato Inter-asociativo de lucha contra la exclusión social", a program carried out in Paris's periphery with the intention of promoting, through soccer, the social ties of people suffering exclusion and social stigmatization. It analyses the history of the championship, his organization, his team composition and the activities related to soccer. Though the author concludes that the sport is not a infallible solution to social integration, he highlights the significance of the program in terms of ensuring a space of coexistence, interaction, motivation and discipline.

\section{Key Words}

Integration, social inclusion, social exclusion, football, respect, coexistence 
El fútbol no se puede medir

Johan Cruyff ${ }^{2}$

Con la presencia hemos ganado

Tousaint Bagou ${ }^{3}$

Queremos buscar la proximidad ahí donde

hay distancia social

Benoît Danneau ${ }^{4}$

\section{Introducción}

De acuerdo con Jaques Defrance ${ }^{5}$ el deporte ocupa hoy en la cultura un lugar importante, en la medida en que marca simbólicamente el espacio social y los momentos de la vida colectiva. Terrenos de juego, entrenamientos los sábados y domingos por la mañana, tardes y noches de final de torneo, gestos y maneras de ser, cuya significación construye progresivamente la vida en sociedad. El deporte es para Bodin, Robène y $\mathrm{Heas}^{6}$ un poderoso elemento revelador de nuestras sociedades, de sus transformaciones, de sus culturas y de la canalización de las expresiones de los individuos. Asimismo, Norbert Elías y Eric Dunning ${ }^{7}$ decidieron incorporar al deporte como uno de los elementos del proceso civilizador al concebirlo como una arena codificada por reglas y límites temporales.

Existen, en este sentido, dos miradas sobre los deportes modernos. Se los asocia, de un lado a mecanismos de integración, de inclusión, de educación y de formación de valores; mientras por otro se los considera un instrumento de manipulación, una herramienta política ${ }^{8}$ destinada a enmascarar los problemas sociales, tras juegos de mero espectáculo. Dado que reconocemos que el deporte ha nutrido ambas visiones, en este trabajo destacaremos los elementos involucrados con la primera postura.

Tal es así que frente a fenómenos como el aumento de la pobreza a nivel mundial, la marginación, los conflictos regionales, los movimientos de inmigración en masa y la exclusión social, la ONU acompañada por la Unesco y la Unicef promueven programas de ayuda a poblaciones en dificultades a través del deporte. A esta tendencia han debido sumarse la FIFA y la UEFA, canalizando parte de sus ganancias en programas e iniciativas con fines sociales. En el caso particular de Francia, el Ministerio del Deporte y la Juventud ha movilizado los deportes colectivos desde los años 80 para hacer frente los crecientes fenómenos de exclusión, en particular aquellos que azotan las llamadas banlieues o suburbios urbanos.

El apogeo de esta idea encontró en Francia su máxima expresión luego de la victoria de la selección de fútbol, les bleu, en el mundial de 1998, y posteriormente, en la Euro 2000. Diversos medios, entre los cuales destacan el diario deportivo de mayor prestigio: I'Equipe adoptaron el eslogan de un equipo ganador integrado por "negros, blancos y árabes". ${ }^{\circ} \mathrm{El}$ fracaso en el mundial de Corea y Japón del

\section{Cruyff, J. citado por Valdano J. (2002) El miedo escénico y otras hierbas, Madrid: Santillana, p. 94}

3. Frase usada por el capitán del equipo de Francia en la Homeless World Cup 2006 convocar a su equipo para el inicio del campeonato contra la exclusión del 2007 en Francia.

4. Extracto de una entrevista personal realizada el 6 de diciembre del 2007. Danneau es el responsable de la asociación Remise en jeu collectif.

5. Cf. Defrance J. (2000) Sociologie du Sport, París : La Découverte.

6. Bodin, D. Robène, L. y Héas S. (2004) Sports et violences en Europe. Bruxelles, Concil of Europe Publishing. Edition du Conseil de l'Europe, p. 5.

7. Elías N. y Dunning E. (1986). Quest for Excitement, Sport and Leisure in the Civilizing Process. Basil. Blackwell Ltda.

8. Existen un gran número de ejemplos donde el deporte fue utilizado para fines políticos. Scher, A. y Palomino, H. analizaron el empleo que el gobierno de Juan Domingo Perón dio en Argentina a los "jóvenes atletas de la nación". Cf. Scher A. et Palomino H. (1986). Fútbol: pasión de multitudes y de élites. Buenos Aires: Cisea.

9. El eslogan en francés es: « noir, blanc et beurs». 
2002 al igual que otros hechos de la vida social $^{10}$ y deportiva ${ }^{11}$ hicieron que la idea de la integración social vinculada al fútbol perdiera valor y peso mediático. No obstante, luego de la labor realizada en el mundial de Alemania 2006, algunos ecos sobre la integración por medio del deporte han vuelto a surgir. En paralelo al boom mediático que se despierta en Francia en función de los éxitos y fracasos de su selección mayor de fútbol, existen varias iniciativas de ONGs que se han abocado a promover el deporte con una alta preponderancia del fútbol. Gran parte de ellas surgieron incluso antes del mundial de 1998 y continúan hasta la fecha con la misma tónica. Este tipo de iniciativas llevan a cabo una creciente participación de diversos actores y de alianzas estratégicas.

El presente trabajo presenta un análisis de un año de investigación micro-sociológica sobre un programa que se encuadra bajo el espíritu de la integración y la inserción social mediante la promoción del fútbol. Se trata del campeonato interasociativo de lucha contra la exclusión social que se desarrolla en el bosque de Vincennes en la periferia de París. Una de las particularidades del mismo es que desde el 2004 un equipo representativo de Francia es seleccionado para participar en la Homeless World Cup, cuyo inicio se remonta al 2003. El trabajo realizado consistió en observar el desarrollo de un campeonato que pretende fomentar los vínculos sociales de personas que por diversos motivos cayeron situaciones de exclusión y estigmatización social. Para ello se analizaron la historia del mismo, su organización, la composición de los equipos y las actividades realizadas relacionadas con el fútbol. El trabajo implicó una serie de observaciones participantes, diecisiete entrevistas, además del análisis de varios artículos de prensa. A continuación se presentan los elementos teóricos que encuadran el trabajo, así como parte del análisis y de las conclusiones de la investigación.

\section{La integración y la inserción social}

Los conceptos de integración e inserción suscitan vivas polémicas y controversias entre los sociólogos en cuanto a su significado. Desde fines del siglo XIX el término de integración estaba reservado por Emile Durkheim ${ }^{12}$ al problema de la sociedad en su conjunto. Así, el padre de la sociología francesa hizo del concepto de integración uno de los ejes medulares de su pensamiento. Para Durkheim la integración estaba ligada al nivel de cohesión social producto de la división social del trabajo y de la solidaridad orgánica. ${ }^{13}$

Los conceptos propuestos por Durkheim siguen siendo hasta la actualidad una fuente de inspiración y debate tanto en el ámbito teórico como en el analítico. De esta manera, Dominique Schapper, especialista en cuestiones de integración enuncia que:

Cuando pensamos en Durkheimy evocamos la regulación, la integración, el hacer sociedad o los lazos sociales, la interrogación es la misma. La cuestión tiene que ver con la integración de los individuos a la sociedad y con la integración de la sociedad en su conjunto". Schapper insiste sobre el hecho que: "la integración en sentido sociológico es, evidentemente problemática, es decir, debe ser objeto de reflexión critica del conocimiento para la investigación. Tratándose de la integración en sentido sociológico, no se la puede reducir a la dimensión étnica (o cultural) y obviar la situación económica y social de

10. A pesar de que los problemas de violencia en las banlieue francesas no constituya un elemento del presente trabajo, la realidad indica que la integración social es una cuestión muy sensible en este momento.

11. Episodios en el fútbol en los que se chifla la Marsellesa, como en 2001 en el estadio de Saint-Denis, durante un partido entre Francia y Argelia, cuando jóvenes invadieron el campo en señal de protesta o en el último Francia / Marruecos, en noviembre del 2007, cuando abuchearon al himno y a los jugadores blancos, constituyen ejemplos de la falta de la integración y de las tensiones sociales. Problemas que no han sido remediados por el deporte y menos por el espectáculo deportivo. acentúa la interrelación y la codependencia entre individuos. Este tipo de solidaridad se opone a la solidaridad mecánica propia de las sociedades tradicionales. Cf. Durkheim (1986) Op. Cit. 
las poblaciones marginadas. El empleo sociológico del concepto implica necesariamente un análisis de las situaciones y de las relaciones sociales. ${ }^{14}$

Existen, además, sutiles diferencias entre la noción de integración y la de inserción. En Francia, el concepto de integración es generalmente una referencia a la situación de los inmigrantes mientras que la inserción es un término que hace alusión a los mecanismos por los que el individuo encuentra un trabajo o un lugar en la sociedad. Ahora bien, si nos referimos a la integración y a la inserción como formas de inclusión es menester invocar el fenómeno inverso: la exclusión social. Norbert Elías ${ }^{15}$ mediante un estudio sociológico conjunto con John L. Scotson en un suburbio de Leicester en Inglaterra, constató bajo su modelo de established y outisiders ${ }^{16}$ que la exclusión no es un fenómeno abstracto, sino que tiene que ver con relaciones sociales de poder. Los autores afirman que en todas las relaciones existen dimensiones de poder, el problema yace cuando la exclusión se vuelve un fenómeno que abarca a grandes capas de una población. De acuerdo con Michel Wieviorka la exclusión: "afecta el sentido en que toda persona es susceptible de posicionar su existencia remetiéndose a temas como la autoestima, el respeto, la dignidad y el amor propio. La exclusión puede ser un nido de odio y rabia". ${ }^{17}$

Alain Touraine $^{18}$ hace una distinción importante entre los términos in y out de manera similar al modelo propuesto por Elías y Scotson (1965). Los in representan a las personas integradas y los out los excluidos. Robert Castel ${ }^{19}$ prefiere, sin embargo, hablar de procesos de desafición para designar las consecuencias de las metamorfosis sociales y los procesos de exclusión.

En una versión dualista de la sociedad, la exclusión o la frontera entre los in y los out comporta de acuerdo con los sociólogos Duret y Augutini tres dimensiones: la primera tiene que ver con el desfase social, vivido por capas enteras de la población, donde el desempleo se instala y se genera un estado de dependencia de los servicios de asistencia social. La segunda es de orden cultural: los out pueden vivir solamente por una procuración del consumo de los in. $Y$ la tercera tiene que ver con el acceso a la palabra y las redes de poder ${ }^{20}$.

Así, según el sociólogo francés Pierre Bouvier la exclusión hace que el individuo no encuentre los medios aptos par asegurar su independencia económica, social e incluso civil en aquellas personas que no gozan de los privilegios de la inclusión. A las condiciones de incertidumbre debemos agregar, además, los procesos de inmigración que terminan en fenómenos de exclusión a gran escala. En este sentido, frente a la pérdida de consenso, al debilitamiento de los lazos, y a la desconfianza entre las personas ${ }^{21}$ resulta importante considerar si los deportes colectivos promueven algunos aspectos del restablecimiento de los tejidos sociales. De acuerdo con Elías: "Ios juegos deportivos en

14. Schnapper D. (2007) Qu 'est-ce que l'intégration ? París: Gallimard. pp. 17 y 25.

15. Elías N. et Scotson J. L. (1965) Logiques de I'exclusion, Avant propos de Michel Wieviorka (1997) París : Fayard.

16. El estudio de Elías y Scotson en el suburbio de Wiston Parva se sustenta sobre el modelo established and outsiders, es decir "establecidos" y "marginados", en referencia al trato que reciben los nuevos habitantes del suburbio, los marginados, frente a los establecidos. Lo curioso es que el suburbio era antes de la llegada de los nuevos habitantes una zona ya marginada de la ciudad de Leicester. Con la apertura de una serie de usinas, el suburbio se dividió en tres zonas. En la zona uno residían los viejos habitantes, mientras que en la zona dos y tres se instalaron los nuevos inquilinos. Elías y Scotson constataron que durante las horas de trabajo en las usinas los habitantes de las tres zonas convivían sin mayor dificultad mientras que en la vida cotidiana las relaciones adoptaban otra tendencia. Los de la zona uno marginaban a los de las zonas dos y tres.

17. Wieviorka, M. (1997) citado por Elías y Scotson, (1965) Op. Cit., p. 16.

18. Touraine, A. (1992) Critique à la modernité. París : Éditions du Seuil.

19. Castel R. (1995) Les métamorphoses de la question sociale. París: Gallimard.

20.Duret P. et Augutini M. (1993) Sports de rue et insertion sociale, París : INSEP, p. 7.

21. Bouvier P. (2005) Le lien social, París: Gallimard, p. 275. 
general, y el fútbol en particular, constituyen un fructífero punto de partida para la construcción de modelos explicativos de la dinámica de los grupos pequeños" (1994: 263).

Aunque es complejo hablar de integración, de inserción y de los conceptos vinculados a la inclusión por medio de los deportes, la toma de posición del presente trabajo tiene que ver con una integración asociada al fútbol mediante la conformación de un grupo y de los mecanismos que se generan alrededor de un equipo. Dicho de otra manera, el vínculo con la integración tiene que ver con la dinámica grupal. Sin embargo, el vínculo entre la inserción y el fútbol no sería más que una relación indirecta a menos que el mismo se convirtiera en profesión y actividad de tiempo completo, lo cual conlleva otro tipo de problemas que no se tratarán aquí.

\section{Las implicaciones del fútbol en los esquemas de inclusión/ exclusión}

Los sociólogos Nicolás Bancel y Pascal

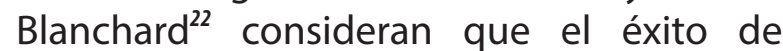
Francia en el mundial de 1998 fue difundido por los medios y por ciertos discursos como la victoria de un modelo republicano de integración alcanzado por el fútbol. Empero, los dos autores argumentan que la integración celebrada no es más que una reproducción del sistema colonial francés.

En una critica aún más severa, Jean Marie Brohm ${ }^{23}$ se refiere al deporte moderno elemento enajenante, portador de una ideología que contiene las mismas características que el capitalismo moderno: la productividad y la competitividad. Según
Brohm, el deporte constituye el opio del pueblo ${ }^{24}$ en la medida en que sostiene valores como la competencia, la apología del jefe o del capitán, la colaboración de clases, la disciplina. En breve, una nueva religión de la época moderna, que bajo esta perspectiva, legitima el orden establecido.

Frente a las críticas de Brohm sobre las dimensiones de enfrentamiento, incluso del posible odio que puede provocar una competencia de fútbol, Pascal Boniface ${ }^{25}$ responde que si hubiera que dejar de lado las dimensiones de ganadores y perdedores habría que suprimir los exámenes escolares, los concursos de administración pública, y todos los concursos de nuestra sociedad. Esto comporta una discusión muy profunda que se extiende mucho más allá del mundo del deporte. Por su parte, el etnógrafo Christian Bromberger, analiza al fútbol como una representación de la vida y se pregunta ¿qué sería de una sociedad o de un mundo enteramente trasparentes donde cada quien tuviera la certeza racional en lo que concierne a rango, puesto, expectativas, etc.? Para Bromberger ${ }^{26}$ el fútbol de hoy: "encarna una visión coherente y contradictoria del mundo contemporáneo. Valoriza el merito individual y colectivo bajo la forma de una competencia que apunta a consagrar a los mejores, pero que a su vez dimensiona también el papel de la suerte y ciertas mañas para llegar al éxito, formas insolentes del mérito".

En este sentido, tanto la visión de Brohm como la percepción de Bromberger ${ }^{27}$ toman en consideración los valores del éxito, el merito individual y la competencia en el fútbol. Sin embargo, mientras que el primero presenta críticas radicales basadas en una

23. Brohm J. M. (1976) Sociologie politique du sport, Delarge J-P. París: Éditons universitaires.

24.La visión de Jean Marie Brohm pertenece a una corriente neo-marxista inspirada en la escuela de Frankfurt.

25 Boniface P. (2002) La Terre est ronde comme un ballon, géopolitique du football, París : Éditions du Seuil.

26. Bromberger C. (2006) Football, la bagatelle la plus sérieuse du monde, París: Agora.

27. Bromberger mediante sus estudios etnológicos desarrollados en Turin y en Marsella concluye que existen varios tipos de espectadores en los estadios de fútbol: aquellos que asisten a un espectáculo en forma pasiva y aquellos que creen poder influir en los partidos mediante su aliento al equipo de sus amores. Véase también la obra anterior del autor: Bromberger (1995): Le Match de football. Ethnologie d'une passion partisane, París:Éditions Maison des Sciences de l'Homme, p. 50. 
perspectiva crítica sobre la enajenación del fútbol, el segundo propone leer el fenómeno como un producto de situaciones naturales, análogas a las vicisitudes de la dinámica de nuestras sociedades. En cambio, para Patrick Mignon $^{28}(1998)$ explorar el mundo del fútbol es ingresar a las profundidades de la cultura popular contemporánea. El fútbol representa para Mignon un modo de construcción de identidades colectivas y de relaciones entre clases, géneros y razas. ${ }^{29}$

Ahora bien, en lo que respecta a las dimensiones sociológicas que intervienen efectivamente en un partido, Elías y Dunning subrayan las polaridades presentes en el fútbol, propias de la lógica interna del enfrentamiento entre dos equipos: la polaridad entreataquey defensa en un mismo equipo; la tensión y la cooperación entre dos equipos para que el juego se desarrolle por causes normales; finalmente, la polaridad entre cooperación y competencia al interior de cada equipo (1994: 325). Vemos entonces que el fútbol provoca posiciones propias de lecturas e interpretaciones antagónicas.

Ser objeto de fuertes polémicas en el mundo intelectual no ha impedido al fútbol transformarse en un hecho social ${ }^{30}$ de primer orden en la mayoría de los países del mundo. Elevado a tal estatuto constituye un espacio de interacción, que según la socióloga del deporte Dominique Baillet se inscribe: "como un hogar importante para la socialización". Para Baillet: "el término de grupo puede designar un club, una sección o un equipo, que se estructura según lógicas afines (culturales, profesionales, etc.) en las cuales los individuos se vinculan mediante prácticas, sentimientos y representación de intereses". Baillet considera que: "un grupo deportivo tiene como función prolongar la socialización familiar"131

Precisamente bajo esta perspectiva el fútbol adoptó un lugar importante en los dispositivos puestos en práctica en Francia a partir de los años ochenta: animaciones en los barrios, operaciones de prevención en verano e incitación a las actividades en los clubes locales.

Michel Fodimbi ${ }^{32}$ reconoce de esta manera que el fútbol puede servir como medio para encausar a jóvenes en situación de vulnerabilidad, en la medida en la que aliente:

- El respeto hacia el otro, adquirido mediante el aprendizaje de las reglas del juego, lo cual puede también desarrollar capacidad para respetar las reglas del juego en la sociedad

- El respeto de sí mismo mediante una práctica deportiva sana y una vida higiénica y comportamientos que confluyen con un mayor autocontrol

- El respeto al arbitro como representante de la autoridad

- El respeto relacional y el valor de la camaradería

- Aptitudes de «empleabilidad» como puntualidad, adaptabilidad y tenacidad

- Valores morales tales como el compromiso, la honestidad y el esfuerzo. $^{33}$

Fodimbi expresa que lo anteriormente mencionado constituye un tipo de situación ideal y que: "nada permite pensar que los comunicación, las estructuras y los conflictos sociales así como la violencia en el campo de fútbol.

30. El concepto de hecho social puede ser abordado desde distintos ángulos. Durkheim hizo del mismo uno de los principales elementos de la sociología. Cf. Durkheim E. (1986) La division sociale du travail Op. Cit. y Durkheim E. (1995) Le Suicide, étude de sociologie (1897), París: PUF.

31. Baillet D. (2001) Les grands thèmes de la sociologie du sport, París : L'Harmattan. Logiques Sociales, p. 163.

32. Fodimbi, M. (2002) «Football et intégration sociale » In Un monde foot, foot, foot. Demazière Didier y Nuytens Williams (ed.). Ed. Corlet, p. 13

33. En el mismo artículo Fodimbi concluye que el papel del fútbol no es otro que el de legitimar el orden establecido, esto lo asemeja a la visión J.M Brohm. 
comportamientos sociales valorizados por la práctica del fútbol serán incorporados por los adolescentes al punto de convertirse en los modelos de conducta en su vida cotidiana". En ese sentido es iluso pensar que los problemas urbanos van a cesar por las virtudes de la práctica del fútbol; lo cual nos lleva a cuestionar ¿en qué medida el fútbol puede ayudar a "jóvenes en dificultad"? Precisamente, una crítica a la noción de "joven en dificultad" fue definida por Duret y Augutini ${ }^{34}$ cuando, en los años 90 , realizaban un estudio sobre la situación de los jóvenes de banlieue en la región Parísina. Duret y Augutini concluyeron que ellos no eran más que: "el árbol detrás del cual hay un bosque". Los autores indican que no se debería hablar por lo tanto en forma singular de "jóvenes en dificultad"dado que existen múltiples figuras y formas de exclusión que proliferaron de manera exponencial entre los años 80 y 90.

Por otra parte, se considera que el hecho de jugar o practicar el fútbol no garantiza de manera alguna la plena inserción social ni comprende todas las dimensiones que Schapper evoca sobre la integración: las facetas culturales, la económica o la dimensión social (2007: 25). Empero, el fútbol en tanto deporte colectivo puede estimular la creación de lazos sociales, lo que puede desembocar en diversas formas de reinserción social. Esta postura sustenta la observación del desarrollo del campeonato interasociativo de lucha contra la exclusión social en Francia.

\section{El campeonato interasociativo contra la exclusión social}

De acuerdo con las estadísticas de la ONU, para el 2006 existían alrededor de un billón de homeless en el mundo. Solamente en Estados Unidos se calcula que hay cerca de 3.5 millones de personas sin domicilio fijo. En Francia el $30 \%$ de las personas sin hogar son inmigrantes. Cabría por lo tanto citar las estadísticas de la Homeless World Cup, según las cuales, de los 500 jugadores que participaron en la edición 2005 en Edimburgo, un 77\% ha cambiado positivamente su vida. ${ }^{35}$

Un análisis del trasfondo de las estadísticas buscó estudiar la evolución y las estructuras detrás de esta competición mundial. Para ello se tomó en consideración el caso particular de Francia y allí la iniciativa Remise en jeu collectif, creada por ocho asociaciones sin fines de lucro, que busca promover valores y estímulos para la reinserción social mediante los deportes colectivos, particularmente a través del fútbol. Esta asociación pone en marcha encuentros deportivos a lo largo del año, entre los que destaca el campeonato contra la exclusión social. Allí participa también la asociación Últimos charrúas ${ }^{36}$ cuyo objetivo es facilitar y consolidar la integración de uruguayos residentes en Francia.

La labor de la iniciativa y del campeonato reside en favorecer la integración social mediante equipos compuestos por personas en distintas situaciones socioeconómicas. Esto mediante el encuentro entre personas que afrontan dificultades: gente sin domicilio fijo ${ }^{37}$, inmigrantes sin papeles, exiliados, y personas que adhieran a la lucha contra la exclusión social. Uno de los mecanismos para promover la integración social por parte de los organizadores del campeonato es recurrir al movimiento del voluntariado ${ }^{38}$; que forma parte de uno de los componentes

35. Datos obtenidos en línea, del sitio oficial de la Homeles World Cup: www.homelessworldcup.org recuperado el 24-01-08.

36. Últimos charrúas se refiere a cuatro indios charrúas: Senaque, Tacuabé, Vaicama Pirú et Guyunusca provenientes de Uruguay llevados por la fuerza a Francia 1883 para ser estudiados "científicamente". Debido a la falta de interés suscitada, los mismos fueron cedidos a un circo Parisino. Tres de ellos murieron debido a los maltratos a los que fueron sometidos. La leyenda indica que uno de ellos: Tacuabé, pudo escapar.

37. Denominados en Francia SDF (sans domicile fixe).

38. En el voluntariado francés participan miles de estudiantes, jóvenes e incluso jefes de empresas. Para un análisis del mismo Cf. Ferrand-Bechmann, D. (2004) Les bénévoles et leurs associations. Autres réalités, autre sociologie? París: L'Harmattan. 
del modelo francés, no sólo del deporte sino de la vida cívica cuya injerencia es notable en el mundo del fútbol amateur.

La iniciativa constituye una red de acción pública en la que participan distintos actores sociales como la Alcaldía de París y el club de primera división París Saint-Germain (PSG), el cual además de prestar las instalaciones del Parque de los Príncipes ha ayudado a preparar a los equipos que viajan a la Homeless World Cup. Si utilizamos la teoría Crozier y Friedberg, ${ }^{39}$ los clubes en tanto actores tienen intereses definidos y actúan conforme a interacciones estratégicas en sus decisiones. Evidentemente, acciones como la del PSG no se hacen sólo por cuestiones altruistas $^{40}$ sino también por objetivos de imagen. ${ }^{41}$ Empero, si los clubes de fútbol de primera división se interesaran con más frecuencia por este tipo de iniciativas, promoverían importantes canales para el desarrollo de actividades sociales.

Resulta importante considerar que si se construyen puentes entre actores públicos y privados, una acción pública entorno al fútbol sería posible. Según Patrice Durán las transformaciones de la acción pública se acompañan de la participación explícita y significativa de actores privados tanto en la formulación como en la puesta en obra de políticas públicas (1999: 11). Durán advierte, sin embargo, que la multiplicidad de actores puede aumentar los conflictos de interés, así como la fragmentación de las intervenciones. El grado de conflicto dependerá de la envergadura de la acción pública. ${ }^{42}$

\section{Análisis de la investigación}

A continuación se presentan algunos extractos representativos de las observaciones y entrevistas efectuadas. En primer lugar se da lugar a la visión de los responsables del torneo y luego se coteja la visión de los integrantes de los equipos.

La primera persona entrevistada fue Benoît Danneau, ${ }^{43}$ presidente de la asociación Remise en jeu. Mediante su relato supimos que el trabajo comenzó en 1993 cuando, en un albergue para personas sin domicilio fijo, una persona de la calle propuso la creación de un equipo de fútbol para hacer frente al aburrimiento y al ocio del fin de semana. Con el tiempo un equipo fue constituyéndose y fueron generándose encuentros con equipos de otras asociaciones civiles. Fue así que poco a poco se diseñó la idea de organizar un campeonato. Danneau explica así que el perfil de aquellos que han adherido al campeonato tiene que ver con: "personas que aman con pasión el fútbol pero que por una razón u otra no pudieron dedicarse a él en forma profesional".

Hoy en día, con varios años de experiencia, el fútbol es un vehículo para iniciar trabajos de reinserción social de personas en situación de precariedad por parte de la asociación Remise en jeu. Según Danneau: "en 19931994 queríamos simplemente jugar al fútbol, con el paso del tiempo nos fuimos dando cuenta de la potencialidad y de los efectos sociales que ello traía aparejado. Es así que pudimos observar los lazos sociales que empezaron a generarse". En 2005 el

39. Crozier, M. et Fridberg E. (1977) L'Acteur et le système, París :Édition du Seuil.

40. Desde el punto de vista de la sociología no existen los agentes neutros, todo actor tiene intereses específicos y estrategias complejas para alcanzar objetivos. Véase Accarado Alain (1983).

41. EI PSG ha sido a lo largo de los últimos años sujeto de fuertes críticas debido a sus malas campañas deportivas, su corrupción interna, su relación con grupos de ultra derecha en sus tribunas como los Boulogne Boys. El 23 de noviembre del 2006 luego de un partido de Copa UEFA entre el PSG y el Hapoël Tel-Aviv, un grupo de 80 miembros de los Boulogne Boys persiguieron a un aficionado de origen judío para golpearlo. Este último fue protegido por un policía de civil de origen antillano. Los Boulogne Boys enfurecidos golpearon en el piso a ambos. Al verse desbordado el policía hizo uso de su arma. Al disparar mató al joven Julien Queremer. La primera muerte ligada al fútbol en Francia. Ahí comenzaron los debates y las críticas al club por haber alimentado durante años el vínculo con este tipo de grupos.

42. Sobre el concepto de acción pública Cf. Thoening, J. C. (1997) Política pública y acción pública, México: Revista Gestión y Política Pública, Vol 6 No 1.

43. Danneau mostró su acuerdo con la investigación y permitió el desarrollo de la misma. 
campeonato tuvo la incorporación de un grupo de aficionados del PSG, los SuprasAuteuil, quienes hicieron gestiones para que el club participara en la iniciativa y prestara sus instalaciones para jugar las finales. Al crecer en importancia la Alcaldía de París tomó cartas en el asunto y empezó a financiar parte de estas actividades.

En cuanto a los efectos del campeonato, Danneau expresa que: "una vez en el campo de juego poco importa quien es quien, nadie se pregunta sobre la situación social o económica del otro. Los jugadores colaboran los unos con los otros". Este es justamente uno de los tipos de interacción que toman forma entre los voluntarios y las personas en dificultad. En tal sentido, Christophe Aubin, responsable de uno de los equipos, el CASH de Nanterre, ${ }^{44}$ considera que: "rápidamente un espíritu de equipo se creó, lo cual alimentó amistades y relaciones sociales".

La conformación de redes sociales puede vincularse en ese sentido al concepto de Robert Putnam ${ }^{45}$ sobre capital social. Normalmente, cuando de una forma de capital social esporádico se llega a la composición de un espíritu en común es posible que las interacciones concluyan en un tipo de capital social denso, el cual conlleva una alta periodicidad y proximidad entre los miembros de una red. ${ }^{46}$ Aubin apunta que:

En nuestro equipo varias nacionalidades se entremezclan. Ello impone la comprensión de la cultura, el ritmo y el espíritu de juego del otro. Hemos percibido diferencias de estilo entre jugadores de Camerún, Irán o Francia. Es necesario aceptar al otro, ser menos egoísta o egocéntrico. Hay ahí un medio de tolerancia y convivencia armónica que se puede construir en torno a un equipo de fútbol.
Así, si cruzamos las tesis de Elías y el trabajo hecho por la asociación Remise en jeu observamos que para Elías (1986) los deportes modernos constituyen un espacio donde los individuos buscan descargar una serie de tensiones, bajo de un esquema de reglas interiorizadas. Por tanto, el trabajo que realiza la asociación implica utilizar al fútbol como un espacio que sirve para aprehender reglas y normas de comportamiento. Danneau ilustra este aspecto de la siguiente manera al referirse a personas en situación de marginación: "el fútbol permite reencontrar la capacidad para cooperar y construir con el otro. La reinserción se efectúa primero mediante la adaptación a un grupo y ese grupo, por extensión, representa a la sociedad". En consecuencia el fútbol puede ser leído aquí como una analogía, una representación de la sociedad en pequeña escala, donde se mezclan la cooperación y la competencia, los objetivos individuales con los colectivos, así como las reglas citadas anteriormente y mencionadas por Fodimbi. ${ }^{47}$ Vemos entonces que la asociación Remise en jeu utiliza el fútbol como una especie de entrenamiento para otras esferas de la sociedad como el trabajo e incluso la familia.

Precisamente, Canzani, el responsable de la asociación uruguaya Últimos charrúas, explica que: "el fútbol es uno de los vectores principales de la asociación dado que es el motor que nos permite reunirnos periódicamente. Intentamos así agrupar varias generaciones de uruguayos que viven en París". ${ }^{48}$ De la misma manera, Canzani afirma que: "el fútbol constituye una herramienta importante, a partir de ese lazo común buscamos organizarnos para otras actividades". Aubin, por su parte, ha constatado que para los integrantes del equipo de Nanterre:

44. Nanterre es parte de la metrópoli pegada a París.

45. Putnam, R. (1993) Making Democracy Work. Civic Traditions in Nothern Italy. Princeton University Press, New Jersey.

46. Cf. Putnam R. (ed.) (2003) El declive del capital social. Barcelona: Galaxia Gutemberg Círculo de lectores.

47. Fadibi, Op, cit.

48. Las actividades de la asociación Últimos charrúas no se limita al fútbol sino que tiene que ver también con la realización de actividades culturales. 
La actividad física es uno de los factores de ayuda, mas no la finalidad de reinserción. El fútbol implica ánimo, energía y placer, una cita importante en la semana que permite la expresión, y la liberación de tensiones. El fútbol contribuye a la reorientación de las personas y su comportamiento general. Los trabajadores sociales señalan un alegría más grande en la vida de las personas en dificultad, mayor vigor y mayor combatividad.

No obstante, importa subrayar que las personas que han iniciado cambios personales, como Danneau lo explica, son: "personas en situación de precariedad que buscan mejorar su situación mediante el esfuerzo y el compromiso". Este comportamiento se ve reflejado en los terrenos de fútbol: "las personas que vienen a entrenar y jugar cambian de motivación, y sobre todo cambian su mirada con respecto a sí mismos". Aubin destaca el esfuerzo hecho, sobre todo en las primeras etapas de la puesta en práctica del equipo de Nanterre: Cada vez que nos juntábamos era una nueva aventura no exenta de desilusiones y tensiones. Muchas veces había que enfrentar el frío y el cansancio, sin embargo, los jugadores estaban siempre presentes [...] Todo ello fue generando no sólo objetivos sino un apego y un sentido de pertenencia a un grupo. Para personas en situación de vulnerabilidad emotiva ello constituye incluso un momento de afecto. Su situación evoluciona y el fútbol tiene que ver con ello.

Las personas a quienes está destinado el campeonato contra la exclusión han conocido diversos pasajes en su proceso de reinserción. Los recorridos de reinserción no han sido lineales, los testimonios indican recaídasy progresos en momentos diferentes. Danneau expresa que: "la plena inserción es difícil de alcanzar ya que siempre existen riesgos de caídas". Las situaciones por las que han transitado estas personas implican graves estigmas. El sociólogo canadiense
Erving Goffman, en su trabajo Stigma ${ }^{49}$, definió la estigmatización de una persona como todo atributo que la descalifica en las interacciones con los demás. Nizet y Rigaux explican que el atributo que descalifica implica una distancia con respecto a las expectativas normativas de la identidad del individuo estigmatizado (2005: 27). Así, una persona resulta estigmatizada por el lazo entre el atributo que estigmatiza (desempleo, discapacidad física, pasado tortuoso, idioma, raza, preferencia sexual, religión, género, etc.) y el estereotipo que se asocia al atributo.

De acuerdo con la sociología de Goffman (1963), la estigmatización está fuertemente ligada a los ideales de una sociedad. Goffman (1963) denunciaba que los ideales de la sociedad norteamericana tenían que ver con el hombre blanco, joven, exitoso, con un trabajo estable, padre de familia, protestante, sano y deportista. Al convertirse estos ideales en paradigmas los individuos pueden ser estigmatizados según la falta de uno, varios o todos los atributos mencionados (negro o de otra raza, viejo, desempleado, sin familia, homosexual, de una minoría religiosa, discapacitado, drogadicto, etc.). La estigmatización puede ser visible (discapacidad física de diferentes tipos), ligada a comportamientos o situaciones pasadas (antecedentes de drogadicción, pasado en la cárcel, pasado en la calle, etc.), o por la pertenencia a un grupo racial, social o religioso según la sociedad en cuestión.

Si extrapolamos la sociología de Goffman al caso parisino, los ideales presentarán matices similares a los norteamericanos con una particular importancia de la posición burguesa en la sociedad..$^{50}$ De esta manera, para las personas que forman parte de los programas de ayuda de la asociación Remise 
en jeu collectif, la estigmatización proviene de varias situaciones de exclusiones pasadas o actuales: haber dormido en la calle, vivir en los alberges para personas sin domicilio fijo, desintegración familiar, carecer de trabajo fijo, estable y bien remunerado, haber llegado a Francia sin papeles, y en varios casos no dominar el idioma francés. ${ }^{51}$

Sobre las personas sin domicilio fijo Pierre Bourdieu expresaba: "aquel del que se dice que no tiene lugar ni domicilio fijo no tiene, prácticamente, existencia social debido a la posición relativa de sus localizaciones temporales y sobre todo a las permanentes con respecto a los demás agentes". ${ }^{22}$ De ahí la importancia de las actividades que permitan a personas sin domicilio iniciar cambios graduales y sustanciales en sus vidas.

El análisis efectuado mediante la observación y las entrevistas abiertas a varios de los participantes del campeonato proyecta una gran gama de situaciones, visiones y procesos de construcción de identidades bajo los términos de Goffman ${ }^{53}$ (1959, 1963, 1967) así como los de Elías y Dunning $^{54}$ (1986). Se buscó entonces cotejar el impacto del fútbol en personas para las cuales tiene significaciones que van de la alegría de vivir hasta la huída de la realidad, según los testimonios recabados. En este sentido, según Danneau: "las personas que constituyen el núcleo duro del campeonato representan un motor para los demás".

\section{Visión de los participantes del campeonato contra la exclusión}

La primera persona entrevistadafueToussaint
Bagou $^{55}$, en su calidad de capitán de uno de los equipos del campeonato y capitán del equipo francés en la Homeless World Cup del 2006 en Sudáfrica. Así, cuando Bagou habla del papel que el equipo de fútbol juega en su vida menciona que le permite hacer una actividad el fin de semana, y que lo: "obliga a llevar una disciplina y no hacer tonterías". Bagou muestra el costado lúdico del deporte pero también el control del comportamiento que conlleva la actividad. Al subrayar la importancia de haberse unido al campeonato contra la exclusión expresa lo siguiente:

Pasé momentos muy duros en mi vida, especialmente cuando conocí a este equipo. Estaba prácticamente viviendo en la calle, si en ese momento me dejaba llevar por el cansancio y el ocio no sé qué hubiera sucedido en mi vida.

Su compromiso y su permanencia hace que Bagou considere: "tener una familia relacionada con el equipo de fútbol".

Es interesante observar el papel de capitán adoptado por Bagou: ${ }^{56}$

Es una gran responsabilidad, como si fuera un trabajo. Busco dar el ejemplo, trato de mejorar día a día y con ello dar el ejemplo a mis compañeros". El sentido de responsabilidad viene inmediatamente a colación:

No es fácil ser siempre derecho, no es fácil siempre dar el ejemplo, llegar en punto, ser medido y mantener la calma en un partido. Aún si a veces me toca trabajar por la noche, al día siguiente tengo que estar ahí. Nadie me obliga a hacerlo, pero es mi responsabilidad frente

51. Para el caso francés el dominio del idioma constituye una condición fundamental para la integración y la asimilación a la sociedad, su mal manejo constituye uno de los principales factores de exclusión para los inmigrantes.

52. Bourdieu P. (1993) La misère du monde. París : Éditions du Seuil, p. 161.

53. Goffman E. (1963). Stigma: Notes on the management of Spoiled Identity, Englewood Cliff: Printice-Hall. También: Goffman E. (1959). The presentation of self in Every Day Life. New York: Double Anchor.

54. Goffman E. (1967) Interaction Rituals: Essays on Face to Face Behavior, New York: Double Anchor.

55. Toussaint Bagou, de 39 años oriundo de Togo, emigró a Francia en el año 2001. Luego de errar, e incluso pasar noches en la calle se integró al equipo en 2003, y solicitó asistencia social. Hoy voluntario en la asociación Remise en jeu collectif y trabaja en una agencia de seguridad.

56. Sobre este aspecto la entrevista no fue el único punto considerado, sino la observación de la presencia, la puntualidad, el respecto de sus compañeros y el comportamiento de Toussain Bagout en los partidos. 
al grupo. A medida que la confianza aumenta más responsabilidades existen.

Ahora bien, el proceso de convertirse en capitán no fue sencillo: "al principio era cuestionado por algunos compañeros, con el tiempo fui ganando confianza, hoy me siento respetado".

Bagout pone en perspectiva el hecho de que "dentro de este equipo hay personas que no tienen hijos, que no tienen parientes, y los que los tienen no los ven jamás. Para ellos el equipo es todo en sus vidas". En tal sentido, es pertinente hablar de procesos de construcción de identidades individuales y colectivas. Stéphane Paillat ${ }^{57}$, nacido en el sur de Francia, testifica que por medio del equipo pudo establecer: "una red de amigos que hoy son su familia". Gervais Agondanoli, oriundo de Benin ilustra este aspecto de la siguiente manera: "la idea de promover el fútbol como forma de integración permite estrechar lazos y descubrir personas. La integración tiene que ver con la conformación de grupos. Para nosotros la integración es el fútbol". Théodore Amba proveniente de Camerún ${ }^{58}$ comenta que: "el fútbol me ha permitido conocer gente. Hay personas que realmente están en situaciones muy complicadas y sin embargo vienen a jugar todos los fines de semana. Ello es admirable porque se nota que aman el fútbol".

El franco-chileno Felipe González, capitán del equipo francés en la HWC de 2007 indica que: "existe una integración entre las personas que participan en el campeonato. El fútbol ayuda también a mantener la cabeza ocupada, sin embargo la discriminación y las etiquetas no desaparecen". Algunos testimonios son representativos: Bagou relata que: "en una época sentía que no existía, que vivía sin perspectivas. Ahora siento que al jugar al fútbol en un equipo que represento formo parte de algo, de un grupo, con el que juego y construyo un destino". La expresión de Bagou da cuenta del sentimiento de exclusión social y del efecto del equipo en su vida. Este aspecto se vislumbra también la experiencia de Hermann: "cuando estaba en uno de los centros de albergues, un viejo integrante del equipo me invitó a unirme. En esa época me encontraba en una fuerte depresión, la entrada al equipo me permitió cambiar de ideas". Hermann indica que en su periodo sin domicilio fijo:

Me encontraba en una situación difícil, sin esperanzas, veía todo negativo. El hecho de unirme al equipo me hizo darme cuenta que había personas con muchas más dificultades y sin embargo se divertían. Comencé poco a poco a cambiar la mirada y sobre todo a no desesperarme. Hoy vivo con mi familia y trabajo en una agencia contable.

Un recorrido por la vida llena de complicaciones de Patrick M'Beu ejemplifica lo antes expuesto. Fue importante obtener su testimonio mediante una larga entrevista y la construcción de su historia de vida. ${ }^{59}$ Antiguo guardametas de la selección de Rwanda, llegó a Francia en situación de exilio. Al poco tiempo se encontraba en la calle, sin dinero y sin trabajo. M’Beu relata que:

Cuando los militares tomaron el control de la selección (de Rwanda) mostré mi descuerdo. Fui relegado, y me amenazaron de muerte. Para evitar riesgos a mi persona y a mi familia huía Francia. Mis cuentas bancarias fueron congeladas. Durante mucho tiempo no tuve dinero para comer. Cuando encontré asilo me invitaron a participar en el campeonato contra la exclusión. Al poco tiempo pude ingresar al Racing Club de France, donde jugué una temporada. Luego fui transferido al Gant de Bélgica.

En 2007 fue convocado a integrar el equipo de Francia para la HWC. M’Beu debió 
lidiar con su representante y con su club: "no querían que la jugara, decían que eso perjudicaría mi carrera profesional". No obstante, M’Beu se unió el equipo francés pese a las advertencias. Hoy se entrena y pertenece al tercer equipo del París SaintGermain donde espera hacer carrera.

En este sentido, la Homeless World Cup se ha convertido en un premio para aquellos que la han jugado, una fuente de motivación para quienes integran el campeonato contra la exclusión. El goleador de Francia en Dinamarca 2007, Karl Groisbois ${ }^{60}$ explica que: "de un día al otro sentí que me convertía en famoso, la prensa me interrogaba, Erick Cantona me felicitaba. Firmé decenas de autógrafos en Copenhague. Al regresar a París me aplaudieron en mi trabajo. Hoy sigo intentado incorporarme a un equipo profesional, no importa si es de tercera división". Paillat se emociona al decir que: "representar a Francia en una competencia internacional fue un gran orgullo, un premio al esfuerzo y al cambio en mi vida". Bagout pone en perspectiva que el mundial implicó: "darse cuenta que hay que luchar día tras día. Todo lo vivido fue un reconocimiento a nuestro esfuerzo"61. Grosbois va más lejos e indica que:"nuestra experiencia puede servir a futuras generación para observar que desde la miseria se pueden hacer grandes cosas". ${ }^{22}$

OtrodelosefectosdeHWCesmencionadopor el franco-chileno González: "la experiencia me permitió ante todo cambiar la mirada y eliminar las etiquetas que yo mismo tenía".63 Así, cuando González habla de etiquetas refleja claramente los aspectos mencionados respecto de la sociología de Goffman en lo que se refiere a la estigmatización. González es conciente que:

Existen etiquetas que la sociedad pone sobre las personas sin domicilio fijo [...] por ejemplo, la primera tiene que ver con confundir el término situación con condición. Estar sin domicilio fijo es una situación y no una condición de las personas. Además, es una situación que se puede revocar. Empero la etiqueta permanece". González reconoce que él mismo: "tenía una concepción errónea que no era justa, tenía ciertos prejuicios antes de ir a la Homeless World Cup. Fue entonces cuando me propuse ir y dejar de lado los preconceptos. Ahí me di cuenta que la sociedad tiene muchas nociones incorrectas sobre las personas sin domicilio fijo. ${ }^{64}$

M’Beu también da cuenta de la estigmatización sufrida: "cualquier persona puede tener un período difícil y encontrarse en un momento dado sin domicilio, pero no todos se quedan en esa situación. No tener domicilio implica la búsqueda de un techo o un hogar, ello no significa ser infrahumano".

Finalmente, los testimonios de los voluntarios pueden completar la dinámica encarrilada en aras de la integración y la reinserción social. A modo de ejemplo de las entrevistas efectuadas podemos citar a Maël Mosain ${ }^{65}$ quien considera que:

60. Karl Grosbois, francés de 21 años trabaja hoy en la cocina de un restaurante en París, durante meses erró por los circuitos de albergue para personas sin domicilio fijo. Su sueño de ser futbolista profesional se había frustrado cuando no pudo ingresar al centro de formación del equipo de Brest debido a la falta de estudios.

61. A su regreso de Sudáfrica en 2006, el equipo de Francia fue presentado en el Parque de los Príncipes antes de un clásico entre el PSG y el Olympique de Marseille. 60 mil personas aplaudieron de pie.

62. Este último testimonio fue recogido de un artículo de prensa del diario Libération del 31 de julio del 2007. El mismo muestra dos aspectos, por un lado el sentimiento de considerarse un ejemplo, en términos de Goffman (1967) una "sacralización de yo", mientras que por el otro, el mismo actor se muestra como alguien estigmatizado, alguien que viene de la miseria. Sin embargo, la situación socioeconómica del joven Grosbois si bien ha sido difícil y complicada tampoco entra dentro de un cuadro de miseria. Lo que aquí se observa es la doble percepción del individuo con respecto a sí mismo y la mirada de la sociedad hacia él.

63. Felipe González, periodista de formación fue invitado a jugar la HWC debido a su participación activa en el campeonato contra la exclusión. González vive en París, temporalmente, en uno de los centros de albergue para personas sin domicilio fijo en París.

64. González relata que los periodistas que cubrieron la HWC preguntaban qué comían, qué música escuchaban, si alguna vez habían leído un libro, en vez de preguntar por la situación personal de cada jugador.

65. Maël Mosain, joven francés de 21 años es voluntario en la asociación donde desempeña tareas administrativas y de logística, así como algunos momentos en encuentros deportivos. 
Las personas que han sufrido los flagelos de la calle son mayoritariamente un público masculino ${ }^{66}$. Para ellos el fútbol es una forma de orientación. A partir del fútbol muchas personas se han reencauzado y han realizado cosas que sin el equipo no hubieran hecho. Desde alejarse del abuso del alcohol, mejorar su imagen y autoestima, hasta buscar un nuevo empleo [...] Jugar al fútbol les impone rutinas y restricciones en términos de salud además de volver a adoptar el gusto por el esfuerzo.

Podemos observar en la visión del voluntario la doble función del fútbol, que más allá de ser un espacio de diversión ${ }^{67}$, implica una interiorización de reglas y de autocontrol, bajo los términos de la sociología de Elías. Este costado se mezcla con los elementos lúdicos del deporte, Mathieu Quino ${ }^{68}$ acota que el deporte en general permite: "encontrar anclas. No sólo el fútbol [...] los deportes colectivos imprimen el sentimiento de grupal". Así, cuando Quino reflexiona sobre las personas del campeonato indica: "los veo contentos antes y después de los partidos. Veo que aman el fútbol, cuando juegan lo disfrutan".

Luego de meses de observación a los partidos y entrenamientos del campeonato y de las entrevistas con los actores que en él participan es pertinente extraer una serie de conclusiones en cuanto a la integración y la reinserción social.

\section{Conclusiones}

Mediante las cifras estratosféricas de transferencias y salarios de estrellas ${ }^{69}$ de fútbol, los costos actuales de los nuevos estadios en Europa, ${ }^{70}$ las imbricaciones con la política, el dopaje, la corrupción, así como la violencia, estamos hablando aquí de otra cara del fútbol, de otra mirada, y lo más importante, de su potencial como herramienta de política social.

La labor realizada por la asociación Remise en jeu collectif se inscribe en la promoción del fútbol amateur como forma de integración y como estímulo a la reinserción social de personas que por diversos motivos han caído en situaciones de exclusión. No es conveniente, empero, percibir el problema en términos del modelo de Tourrain ${ }^{71}$ entre personas in et out, dado que la multitud de formas de exclusión y sus márgenes son de alta complejidad. En lo que respecta a las personas del campeonato contra la exclusión no se trata de personas que estuvieron, salvo momentos críticos y casos puntuales, totalmente excluidos. Ni se trata hoy en su mayoría de personas altamente integradas a la sociedad francesa.

Por distintos motivos e intereses que no hemos analizado en este trabajo a nivel global hoy se involucran en la promoción del deporte cada día más actores, en particular el fútbol como programa de desarrollo e integración. Las instancias internacionales, los gobiernos, así como nuevos actores, las ONGs, recurren a alianzas estratégicas y a programas de diversa índole. Lo que se puede aprender de la experiencia observada en Francia es que cuando existe la voluntad de instituciones pertinentes y cuando se recurre a la acción pública pueden encararse programas y proyectos socialmente significativos. $^{72}$ El hecho que el Paris-Saint

66. Aunque no es el tema de estudio, sobrevive la inquietud acerca de la situación de las mujeres en condiciones de pobreza o miseria en Francia (inmigrantes y locales). Y cabrá señalar, en este y todos los casos que las opiniones vertidas son de índole absolutamente personal; se observó la repetición también de discursos aprendidos, memorizados de algunos voluntarios.

67. Sobre los elementos lúdicos en el deporte y en la cultura véase Huizinga J. Hommo Luddens.

68. Mathieu Quinot, estudiante de radiología participa en el campeonato contra la exclusión.

69. Cifras que rondan los millones de euros. En cuanto a salarios, David Beckham gana en el Galaxy de los Ángeles un salario de 10 millones de dólares al año, lo cual sumado a la explotación de su imagen le reditúa en alrededor de 50 millones al año. Kaka por su parte, al renovar contrato con el Milán a fines del 2007 consiguió un salario anual de 9 millones de euros, algo así como 750 mil euros por mes, o 2500 euros al día.

70. El nuevo estadio del Liverpool en Stanley Park previsto para el 2011, tiene un costo estimado en 562 millones de euros.

71. Touraine, A. (1992) Critique à la modernité. París: Éditions du Seuil.

72. El subrayado es del autor. 
Germain se involucrara en la iniciativa estudiada es un ejemplo de la dimensión de acción pública. No obstante, el grado de intensidad de dicha acción es aun bajo ya que la participación del club en los próximos años es incierta.

Ahora bien, si pensamos en términos de la sociología de Norbert Elías y Eric Dunning, "jugar o asistir a un deporte se ha convertido en unodelosprincipalesvectoresdeconstituir una identidad en la sociedad moderna, así como dar sentido a su vida para muchas personas" (1986: 306). Este enfoque, igual que el de Goffman $(1959,1963,1967)$ sobre los procesos de construcción de identidades, ayuda a interpretar testimonios y entrevistas a personas para las que el fútbol se convirtió en parte del sentido por el cual reorientaron sus vidas, y proyectaron su identidad ligada al sentimiento de pertenencia a un grupo. El fútbol en este sentido tiene una doble función, por un lado, abre la dimensión de un espacio lúdico, por el otro, la de un espacio socializante con reglas de comportamiento, espacios de interacción y situaciones que exigen autocontrol y disciplina.

Se observa así que para los jugadores del campeonato contra la exclusión social, en especial aquellos que han participado en la Homeless World Cup, el valor de esta competición ha crecido a un punto tal que la asociación Remise en jeu espera poder albergarla en Francia en el 2011. Por su parte, la asociación Últimos charrúas realiza gestiones para organizar la cita mundial en Uruguay en el 2010. Según Canzani:"Uruguay albergó el primer mundial en 1930, ahora queremos organizar la primera copa del mundo para personas sin domicilio fijo en Latinoamérica". Los jugadores consultados sobre su vivencia en la competición internacional presentan hoy una nueva mirada sobre sus destinos y su situación, lo cual les lleva a actuar y a expresarse de una manera distinta. En resumen, su experiencia los ha conducido a asumir nuevos papeles en sus vidas.

De esta manera, si hablamos de integración bajo los términos Durkheim o de Schapper ${ }^{73}$ podemos decir que existe una mayor proximidad social entre los integrantes del campeonato. Lo que subyace a esta iniciativa puede ser leído, bajo la óptica de Elías y Dunning (1986) como un proceso de "deportización", en el cual se produce una anulación de las diferencias sociales en los terrenos de juego, así como la constitución de un espacio con una temporalidad específica.

A modo de conclusión final podemos sostener entonces que el deporte en general, y el fútbol en particular, no son una solución infalible al problema de la inserción o la reinserción social, afirmarlo sería creer que una herramienta se puede transformar en una respuesta universal. No es el caso, ni el objetivo del campeonato contra la exclusión, ni la postura asumida durante esta investigación.

Si se busca un impacto real y un cambio en el destino de las personas, el fútbol no garantiza por sí mismo más que un espacio de convivencia, de interacción, de disciplina y motivación; si se desea acceder a él, es preciso acompañarlo de otro tipo de políticas públicas. Sin embargo, su potencialidad deja abierta la opción de encarar con más frecuencia este tipo de políticas sociales. Algo urgente que resta por hacer es promover una mayor cantidad de diagnósticos, evaluaciones e investigaciones sobre esta cuestión, enmarcados en el campo de las ciencias sociales. 


\section{Otra bibliografía utilizada}

Accardo A. (1983) Initiation à la sociologie de I'illusionnisme social, Burdeos: Le Mascaret.

Anstett M. et Sachs B. (1995) Sport, jeunesses et logiques d’insertion, París: La documentation française.

Charrier D. (1997) Activités physiques et sportives et insertion des jeunes: enjeux éducatifs et pratiques institutionnelles, París: La documentation française

Duran P. (1999) Penser l'action publique, París: L.G.D.J.

Gasparini W. (2000) Sociologie de I'organisation sportive, Paris: La Découverte. 